\title{
вмJ Global Health Estimated costs of production and potential prices for the WHO Essential Medicines List
}

\author{
Andrew M Hill, ${ }^{1}$ Melissa J Barber, ${ }^{2}$ Dzintars Gotham ${ }^{3}$
}

To cite: Hill AM, Barber MJ, Gotham D. Estimated costs of production and potential prices for the WHO Essential Medicines List. BMJ Glob Health 2018;3:e000571. doi:10.1136/ bmjgh-2017-000571

Handling editor Seye Abimbola

- Additional material is published online only. To view, please visit the journal online (http://dx.doi.org/10.1136/ bmjgh-2017-000571).

Received 18 September 2017 Revised 13 December 2017 Accepted 13 December 2017
Check for updates

${ }^{1}$ Department of Translational Medicine, University of Liverpool, Liverpool, UK ${ }^{2}$ Harvard T.H. Chan School of Public Health, Boston Massachusetts, USA ${ }^{3}$ Faculty of Medicine, Imperial College London, London, UK

Correspondence to Dr. Dzintars Gotham; dzintarsgotham@gmail.com

\section{ABSTRACT}

Introduction There are persistent gaps in access to affordable medicines. The WHO Model List of Essential Medicines (EML) includes medicines considered necessary for functional health systems.

Methods A generic price estimation formula was developed by reviewing published analyses of cost of production for medicines and assuming manufacture in India, which included costs of formulation, packaging, taxation and a $10 \%$ profit margin. Data on per-kilogram prices of active pharmaceutical ingredient exported from India were retrieved from an online database. Estimated prices were compared with the lowest globally available prices for HIV/AIDS, tuberculosis (TB) and malaria medicines, and current prices in the UK, South Africa and India.

Results The estimation formula had good predictive accuracy for HIV/AIDS, TB and malaria medicines. Estimated generic prices ranged from US $\$ 0.01$ to US $\$ 1.45$ per unit, with most in the lower end of this range. Lowest available prices were greater than estimated generic prices for 214/277 (77\%) comparable items in the UK, $142 / 212(67 \%)$ in South Africa and 118/298 (40\%) in India. Lowest available prices were more than three times above estimated generic price for $47 \%$ of cases compared in the UK and $22 \%$ in South Africa.

Conclusion A wide range of medicines in the EML can be profitably manufactured at very low cost. Most EML medicines are sold in the UK and South Africa at prices significantly higher than those estimated from production costs. Generic price estimation and international price comparisons could empower government price negotiations and support cost-effectiveness calculations.

\section{INTRODUCTION}

Lack of access to affordable medicines continues to represent a major global health burden. ${ }^{12}$ A recent analysis found that, based on per-capita pharmaceutical expenditure, a basket of 201 essential medicines was unaffordable in nearly all low-income countries and 13 middle-income countries. ${ }^{2}$ An earlier estimate put the number of people lacking regular access to essential medicines at one-third of the global population. ${ }^{3}$ In low-income and middle-income countries (LMICs), only $58 \%$ of essential medicines are available

\section{Key questions}

What is already known about this topic?

- High prices of essential medicines pose a barrier to their use in many different settings.

- We searched the PubMed database and grey literature using the term (cost ${ }^{*}$ OR price $\left.{ }^{\star}\right) A N D$ (manufacture OR production) AND essential AND (medicine ${ }^{\star} O R$ drug $^{\star}$ ). While the costs of production for a few products have previously been analysed, we did not find any studies on production costs for all medicines on the WHO Essential Medicines List, or any similarly broad group of products.

- This study was commissioned by WHO, who identified this as a gap in the literature.

\section{What are the new findings?}

- The methodology presented in this study can be used to reliably estimate the generic price that can be achieved if profit margins are competitive, for a wide range of medicines.

- We show that prices could fall for most essential medicines in the UK and South Africa, and for nearly half of essential medicines in India. This suggests that even for old and widely used medicines, continued efforts should be made to encourage competitive supply.

Recommendations for policy

- This methodology can be used by governments and international institutions to inform price negotiations.

- Cost of production analysis could be incorporated into government tenders, health technology assessments and medicine price negotiations, allowing a reduction of information asymmetry.

in the public sector, and $67 \%$ in the private sector, according to surveys of pharmacies. ${ }^{4}$ Medicines account for a quarter of all health expenditures globally, ${ }^{2}$ and $100 \%$ of health expenditures for about half of households in LMICs. ${ }^{5}$

Recent high-level groups have recommended greater transparency in drug pricing. ${ }^{2}$ Data on the costs of production for medicines are not publicly available, and 
health systems have limited negotiating power when a medicine is sold in a monopoly situation. However, prices can fall substantially when generic competition is enabled, achieving, for example, price reductions of $99 \%$ in first-line HIV/AIDS medicines. ${ }^{6}$

The WHO Model List of Essential Medicines (EML) was created in 1977 to support national health systems in prioritising drugs for procurement, and includes medicines that are needed to 'satisfy priority health needs of the population', ${ }^{7}$ based on disease burden, efficacy, safety and cost-effectiveness compared with other medicines in the same therapeutic group. ${ }^{8}$

The price of the raw medicine substance, or active pharmaceutical ingredient (API), is generally the most significant component of pharmaceutical cost of production. ${ }^{9}$ This analysis used data of API exported from India to estimate generic prices for all medicines in solid oral dosage forms included in the EML. We have previously undertaken analyses of production costs for viral hepatitis, ${ }^{10} 11$ tuberculosis (TB) ${ }^{12}$ and cancer drugs, ${ }^{13} 14$ using similar methods.

\section{METHODS}

Additional references for this section are given in an online supplementary appendix. Medicines with solid oral formulations from the 2015 EML were included (see online supplementary appendix for excluded formulations). All monetary values are expressed in US dollars.

\section{Country of production}

We assumed API procurement and formulation of finished pharmaceutical product (FPP) in India due to its large generic industry and historical importance in treatment of the HIV epidemic. ${ }^{6}$ The main alternative country to consider as a focus for the analysis was China; for pharmaceutical manufacture, India and China are similar in cost of labour, infrastructure and tax. However, Indian manufacturers have more experience with the WHO prequalification programme (an initiative that certifies the quality of medicines), which currently lists 335 products manufactured in India, but only 23 manufactured in China. ${ }^{15}$

\section{Estimation of API cost}

Data on price per kilogram of API exported from India was collected from an online database (infodriveindia. com) that collects data published pursuant to Indian customs regulations. Prices for exported goods in the database are given in both Indian rupees and US dollars, with the US dollar value calculated based on the exchange rate on the day of the transaction. Search terms used and full exclusion criteria are available in the online supplementary appendix. The default timeframe for API shipments used in the database search was 1 July 2014 to 1 July 2016, and was extended backwards by 2 years until at least 100 records were available, up to a maximum 6-year timeframe.
Linear regression was used to estimate the per-kilogram price on 1 July 2016 of exported API. API price per dose was calculated, and multiplied by a 'salt-factor' for drugs whose dose is expressed in the EML in terms of the active molecule, but for which the API is manufactured in a salt form (eg, an 'erythromycin $250 \mathrm{mg}$ ' tablet contains $360 \mathrm{mg}$ of erythromycin estolate). Stata/IC V.14.0 for Mac was used for statistical analysis of the API dataset.

\section{Costs of excipients}

Typical costs of excipients used in tablets and typical proportion of the FPP made up by each excipient were combined, and excipients were assumed to represent $50 \%$ of total tablet weight. This yielded an estimated average excipient cost of US $\$ 2.63$ per kilogram of FPP (see online supplementary appendix).

\section{Conversion costs}

A number of sources were used to inform an assumed per-unit cost for converting raw API and excipients into an FPP ('conversion cost'). We reviewed reports of capital and operating costs for pharmaceutical tablet formulating plants and contacted large generic manufacturers for confidential estimates. In addition, we identified the product with the lowest price in the UK, South Africa and India: with API cost and profit margins approaching zero for the cheapest products, the total per-unit cost can be seen as a high estimate of the conversion cost. Estimated conversion costs per tablet extracted from these sources are summarised in table 1 , with details and full references available in the online supplementary appendix.

Per-unit conversion costs reported in analyses in the last 10 years (operating cost including depreciated capital cost) ranged from US $\$ 0.0002$ to US $\$ 0.013$ per tablet. The estimate of conversion cost by Chaudhuri and West (US\$0.01 per tablet) included costs of environmental protection and compliance with current Good Manufacturing Practice (cGMP) standards. ${ }^{16}$ The costs attributed to cGMP compliance are similar to costs estimated in an Indian government white paper (see online supplementary appendix). We therefore used a conversion cost of US $\$ 0.01$ per tablet in this study.

\section{Tax and profit margin}

The average profit margin for the pharmaceutical industry in India was $8.8 \%$ in 1995 and $15.4 \%$ in 2005. We assumed a profit margin of $10 \%$. Tax rates in India range from $18.5 \%$ to $34.6 \%$; we assumed a midpoint value of $26.6 \%$ tax charged on net profits. The final price estimation algorithm is shown in figure 1. References are mentioned in the online supplementary appendix.

\section{Current prices in the UK, South Africa and India}

Lowest currently available prices (LCP) were collected from publicly accessible databases. For South Africa, we used public procurement prices published by the National Department of Health. For Tamil Nadu, India, prices were extracted from a list of a medicine tenders, or, if not available from that source, from an online 
Table 1 Per-unit cost component values available from published sources in the last 10 years

\section{Source (year, location)}

Most recent conversion cost 'norms' published under India's Drug (Price Control)

Order 1995 (2012, India)

Lowest-priced product in UK, South Africa, India (2016)

\section{Cost components included in estimate}

CC not including distribution or packaging

Cost per unit of lowest-priced solid oral formulation FPP $\quad 0.0011-0.0043$
Conversion cost per tablet (US\$)

$0.0002-0.001$

'Can local producers compete with low-cost CC including depreciation of capital and packaging, but 0.0056 imports? A simulation study of pharmaceutical not including sales and distribution

industry in low-income Africa', Chaudhuri and West (2015 India)

CC including depreciation of capital and packaging, and $\quad 0.0105$ including sales and distribution

Confidential discussion by authors with large generic companies (2016, India)

CC including packaging, but not depreciation of capital, $\quad 0.006$ sales or distribution

'Outlook on pharma operations' McKinsey \& Total production costs, lowest-cost plants (not further 0.013 Company (2014, no specific territory) specified)

CCC, conversion cost.

database of Indian Maximum Retail Prices. For the UK, prices were extracted from the British National Formulary (BNF) and the drugs and pharmaceutical electronic market information tool (eMit), with the lower of the two used to represent the UK price. The BNF reports 'indicative' prices, while eMit prices represent actual government purchases. In addition, the availability of more than one manufacturer in the UK was noted, as an indicator for generic availability and competition. Details on price sources and exchange rates use are available in the online supplementary appendix.

\section{Validation}

We compared estimated generic prices to global lowest current prices of medicines for which there are global market-managing initiatives, such as the Global Fund. Details on price sources are available in the online supplementary appendix.

\section{RESULTS}

Estimated API price per kilogram, generic price estimates and current prices are given in online supplementary appendix table 2 .

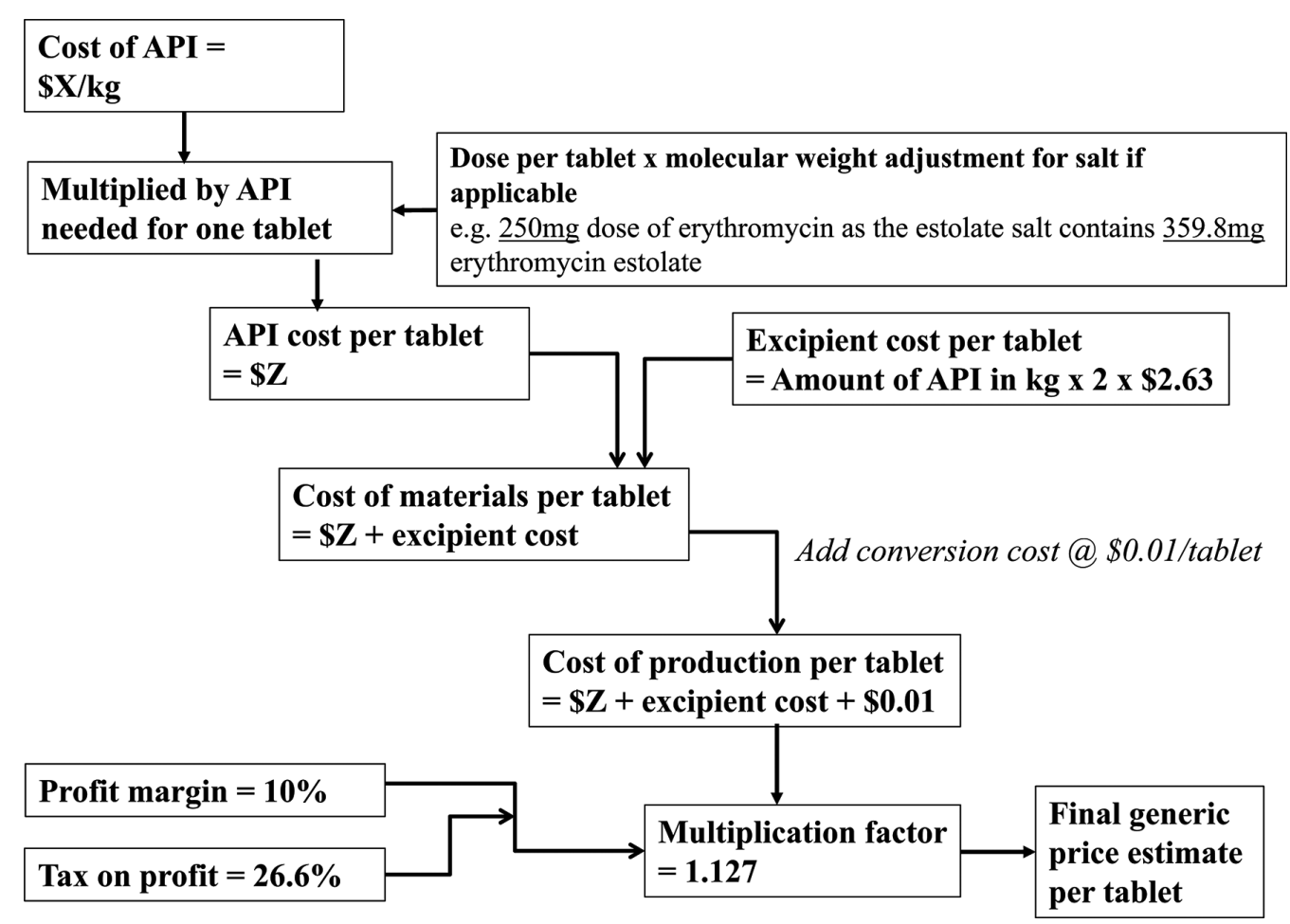

Figure 1 Algorithm used to estimate generic prices. API, active pharmaceutical ingredient. 


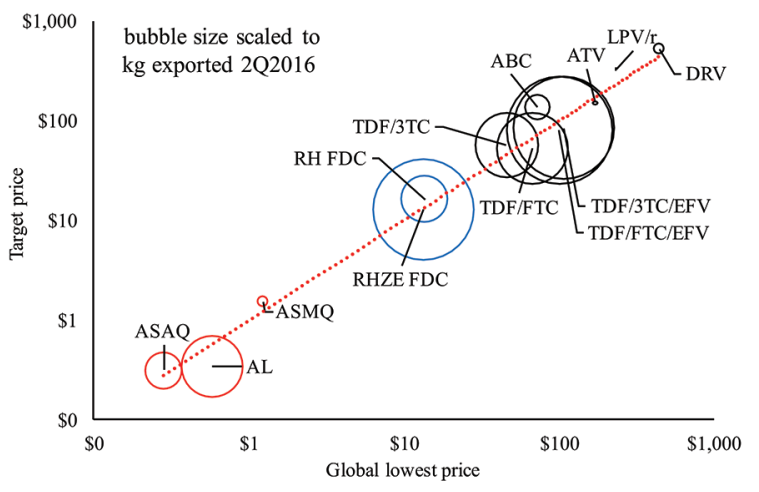

Figure 2 Comparison of current lowest global price vs estimated generic price, for medicines for diseases with large international treatment programmes. Prices reported per treatment course: 1 year for HIV treatments, 6 months for tuberculosis, 3 days for malaria. ASAQ, artesunate amodiaquine; $\mathrm{AL}$, artemether lumefantrine; $A S M Q$, artesunate mefloquine; RHZE, rifampicin, isoniazid, pyrazinamide, ethambutol; $\mathrm{RH}$, rifampicin, isoniazid; TDF, tenofovir disoproxil fumarate; 3TC, lamivudine; FTC, emtricitabine; ABC, abacavir; ATV, atazanavir; EFV, efavirenz; LPV, lopinavir; r, ritonavir; DRV, darunavir; FDC, fixed-dose combination.

There were sufficient API data for 148 medicines on the EML (including 20 fixed-dose combinations or medicines listed as combinations), and for 375 finished pharmaceutical products overall when including various dose forms. For 49 medicines on the EML, production costs could not be calculated due to a lack of data on exported API. Lowest current prices were identified for $73 \%$ of items in the UK, $47 \%$ in South Africa and $75 \%$ in India.

Average API price per kilogram was in the range of US $\$ 1-U S \$ 10 / \mathrm{kg}$ for 5 medicines (zinc sulfate, paracetamol, metformin, acetylsalicylic acid, niclosamide), US $\$ 10-U S \$ 100 / \mathrm{kg}$ for 43 medicines, US $\$ 100-U S \$ 1000 /$ $\mathrm{kg}$ for 58 medicines, US $\$ 1000$-US $\$ 10000$ for 19 medicines and were $>$ US $\$ 10000 / \mathrm{kg}$ for 3 medicines (anastrozole, methotrexate, entecavir).

Estimated generic prices ranged from US $\$ 0.011$ pertablet (glyceryl trinitrate $500 \mu \mathrm{g}$ ) to US $\$ 1.447$ per tablet (darunavir $800 \mathrm{mg}$ ), and were heavily skewed towards lower prices in this range. There were 186 estimated generic prices $<2.5$ cents per tablet, versus only 51 prices above 10 cents per tablet. There was a strong correlation between the estimated generic prices with current global lowest prices for medicines used for HIV, TB and malaria (figure 2). Current lowest UK prices were median $171 \%$ above estimated generic price (IQR 4\%-1230\%), South African prices were median $39 \%$ above estimated generic price (IQR $-24 \%$ to $183 \%$ ) and Indian prices were median $40 \%$ below estimated generic price (IQR $-70 \%$ to $59 \%$ ).

In the UK, prices were above estimated generic price in 214 of 277 (77\%) comparable cases, and more than three times above estimated price in $47 \%$ of cases. LCP were 0.2-387 times the estimated price where multiple suppliers existed, and 3.5-8803 where only one supplier was available. The items with highest LCP to estimated price ratio in the UK were daclatasvir $30 \mathrm{mg}$ (8803x), daclatasvir $60 \mathrm{mg}$ (5063x), sofosbuvir $400 \mathrm{mg}$ (958x), ledipasvir/sofosbuvir 90/400 mg FDC (593x) and dexamethasone $1.5 \mathrm{mg}(387 \mathrm{x})$. Prices were available only in the BNF in 109 cases, only in eMIT in 5 cases. The eMIT price was lower than BNF price in 185 of 209 cases where a price was available from both sources.

In South Africa, 142 of $212(67 \%)$ comparable prices were above the estimated generic price. LCP were $0.2-139$ times the estimated price. The items with highest price ratios were ondansetron $24 \mathrm{mg}(139 \mathrm{x})$, mercaptopurine $50 \mathrm{mg}(106 \mathrm{x})$, ondansetron $8 \mathrm{mg}(90 \mathrm{x})$, omeprazole $40 \mathrm{mg}(32.8 \mathrm{x})$ and haloperidol $2 \mathrm{mg}(25 \mathrm{x})$.

In India, 118 of $298(40 \%)$ comparable prices were above estimated generic price. The items with highest Indian price to estimated price ratios in were zidovudine $250 \mathrm{mg}$ (45x), praziquantel $150 \mathrm{mg}$ (15.5x), capecitabine $150 \mathrm{mg}$ (13.8x), efavirenz/emtricitabine/tenofovir $600 / 200 / 300 \mathrm{mg}$ FDC (10.7x) and efavirenz $200 \mathrm{mg}$ (10.5x). Among prices collected from the database of tenders, LCP to estimated price ratios ranged from 0.04 to 4.3 . Among private market prices, lowest Indian price to estimated price ratios ranged from 0.03 to 45.1 .

Large price variations were seen for many medicines that are presently under patent protection, or were under protection until recently. In many cases, generic medicines had relatively consistent prices, while for some there was notable variation in prices (figure 3 ). The therapeutic group with most price variation was antiretroviral medicines.

\section{DISCUSSION}

This study calculated production costs and estimated generic prices for 148 medicines on the WHO EML, showing that most essential medicines can be manufactured at low cost. Calculation was possible for 148/197 $(75 \%)$ of the medicines meeting inclusion criteria. Despite most medicines on the EML being off-patent, 214 of 277 comparable prices in the UK, 142 of 212 comparable prices in South Africa and 118 of 298 comparable prices in India exceeded the price that would be expected based on cost of production and a $10 \%$ profit margin.

This study used prices of actual, recent sales of API exported from India as the main data input for price estimation. For most medicines, at least 100 export shipments of API were available. Prices of API were generally stable over time, or had a slight decreasing trend (see online supplementary appendix). The estimation formula accounted for capital and operating expenses including labour costs, land and utilities costs, costs of running equipment, costs associated with environmental protection and compliance with cGMP standards, taxation and a profit margin. Validation exercises demonstrated a good ability of the estimation algorithm to predict current lowest global prices for treatments of 
Examples of generic medicines with relatively constant price.

$$
\phi 5.0
$$

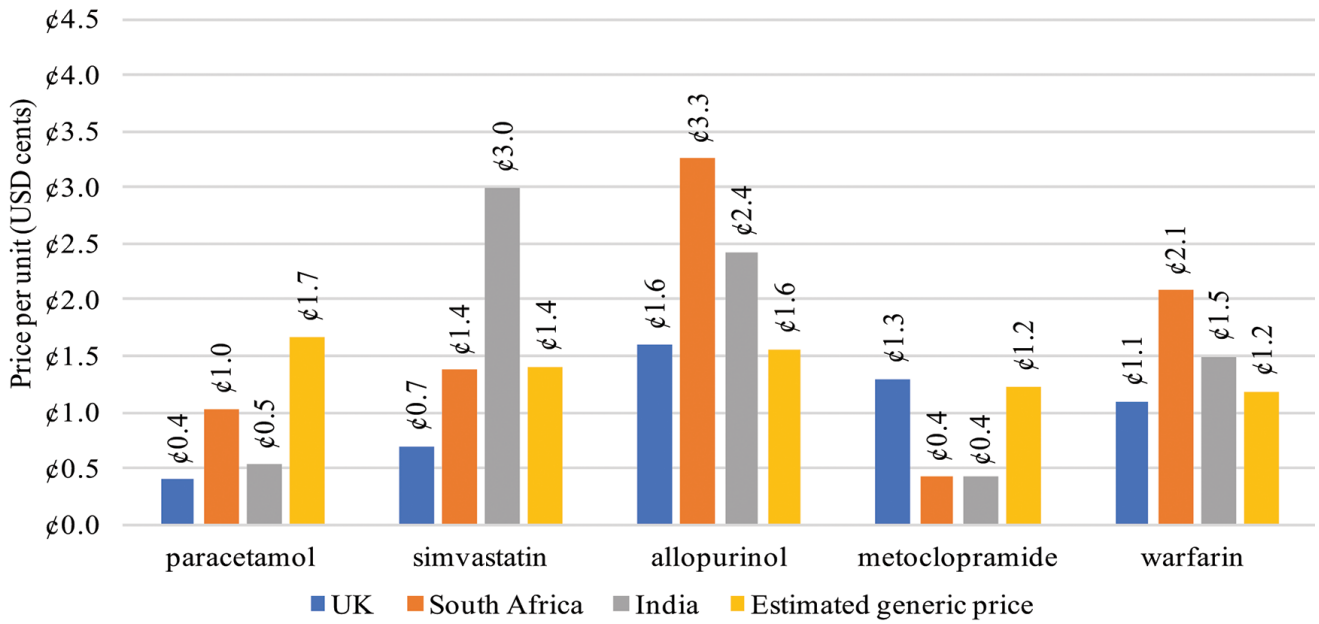

Examples of generic medicines with large variations in price.

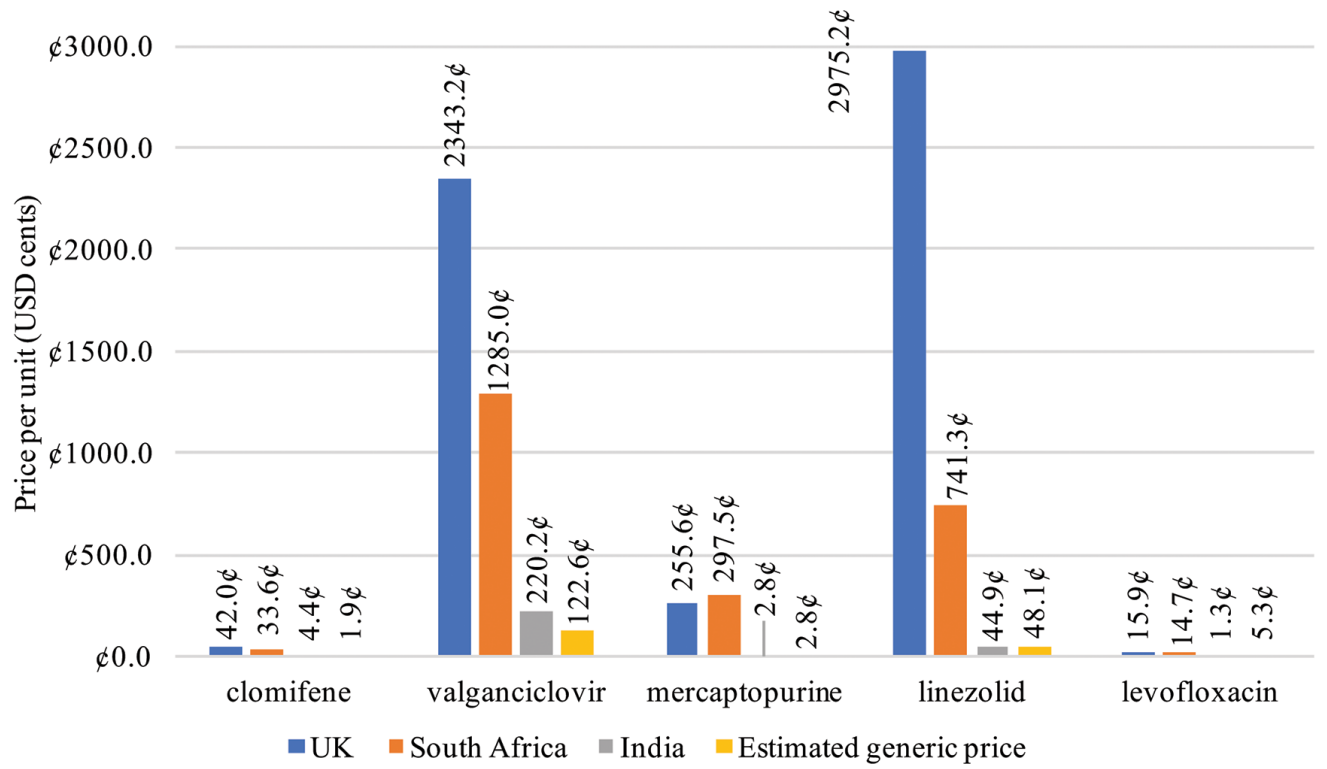

Figure 3 Examples of different patterns in price comparisons. Simvastatin, $10 \mathrm{mg}$; allopurinol, $300 \mathrm{mg}$; metoclopramide, 10 mg; warfarin, 1 mg; clomifene, 50 mg; valganciclovir, 450 mg; mercaptopurine, 50 mg; linezolid, 600 mg; levofloxacin, 250 mg.

HIV, TB and malaria-diseases with large international treatment programmes (figure 2). Lowest current prices in India were higher than the estimated generic price in 118 cases and lower in 180 cases, and median $40 \%$ lower than estimated generic price. This distribution suggests that the algorithm used to calculate minimum costs of production errs on the conservative side (table 1 and online supplementary appendix).

Most of the high-priced medicines in India were found only in the private market price source, and not the (Tamil Nadu) government tender list, suggesting a lack of availability in public facilities. Over $75 \%$ of health expenditure is out-of-pocket in India, of which the majority is spent on medicines. ${ }^{17}$ While we found Indian prices to be below our estimated generic price in many cases, Indian prices were mostly government tender prices, which are likely to be significantly lower than the private market prices more often experienced by those needing medicines in India. Further analysis of the Indian market would be necessary to determine prices available to various facilities, provinces and patient groups.

Generic competition achieved massive price reductions for antiretroviral drugs in the early 2000s. ${ }^{6}$ However, non-communicable diseases (NCDs) now represent a larger disease burden than communicable disease, and similar price reductions in medicines for cancer, type 2 diabetes and anticoagulation may be valuable in enabling wider treatment of NCDs in LMICs. ${ }^{18}$

To protect the right to health, all countries need to ensure affordable access to medicines. This requires avoiding and tackling monopolies, including through legislation, as well as encouraging competition, ensuring a robust supply chain and monitoring shortages and stock-outs. Mechanisms to overcome intellectual property 
restrictions in the public interest include governments issuing compulsory licences and originator companies offering voluntary licences. Both are legal mechanisms that allow the use of patented products (including production, import and use) before patent expiry. ${ }^{1}$ One successful example of voluntary licensing is embodied in the Medicines Patent Pool, which negotiates licences with originator companies, and then sub-licenses production rights to generic manufacturers in resource-limited countries.

The World Trade Organization's Agreement on Trade-Related Aspects of Intellectual Property Rights (TRIPS), which sets minimum requirements and limitations on intellectual property laws globally, additionally provides (in article 31bis) for compulsory licences predominantly for export-meaning that compulsory licences can be granted in countries with large manufacturing capacity (such as India) in order to supply other countries where there is a pressing need. ${ }^{19}$

The TRIPS agreement does not prevent individual patients importing medicines for personal use, regardless of patent status, although national legislation must also permit importation for personal use to make this a viable route for access, and this is not uniformly true. This route is being used by patients to access affordable HIV pre-exposure prophylaxis and hepatitis $\mathrm{C}$ drugs, with evidence of good clinical outcomes. ${ }^{20}{ }^{21}$ However, personal-use importation as a method to overcome to access barriers requires the patient population to be organised and assertive, have a high level of access to information and financial resources and cannot be considered a feasible large-scale solution.

Comparative clinical and cost-effectiveness is assessed both by national regulators such as the UK's National Institute for Health and Care Excellence and the WHO Expert Committee reviewing proposed additions to the EML. Cost-effectiveness calculation depends on the efficacy and available price for the drug and the comparator. Where a novel drug is being compared with a drug that is near patent expiry, a cost estimation exercise can help anticipate the generic price of the latter. Recent examples where this analysis could have been applied include novel oral anticoagulants compared with warfarin, dasatinib as a second-line after imatinib for chronic myeloid leukaemia and dolutegravir compared with efavirenz for the treatment of HIV. Generic market entry of comparators should trigger recalculation of cost-effectiveness for drugs whose assessment depended on comparison with an earlier, higher non-generic price.

Estimation of production cost can improve transparency in pricing negotiations, and there are precedents using cost of production in price control mechanisms. In India, a formula based on costs of manufacture was used to set ceiling prices for 'scheduled' medicines from 1995 until 2013, when legislation changed. ${ }^{22-24}$ In South African government tenders, manufacturers are requested to provide in their bids a breakdown of drug price into API, formulation, packaging, logistics, and 'gross margin' components. ${ }^{25}$ China, Iran, Bangladesh and Pakistan use similar mechanisms. ${ }^{26}$

Further research based on pricing data for API exported from India may be limited by a recent change in Indian law, removing the requirement for daily publication of customs data. ${ }^{25}$ Expanded international price comparisons may identify cases where resource-limited health systems face excessive generic prices.

\section{Limitations}

This analysis was limited by the inability to include an estimate for the costs of product development, bioequivalence studies, registration costs and costs of litigation, due to a lack of published data. This is balanced against numerous factors that may have contributed to overestimation of the API costs incurred by Indian manufacturers, and thus overestimation of profitable generic prices: API prices in export data likely include a profit margin for the API producer, paid by the manufacturer of the FPP-while if API were manufactured in-house by the producer of the FPP, this intermediate profit margin, as well as transport costs and duties would be avoided. Direct assessment of API adherence to stringent regulatory authority standards was not possible from the export data. However, the sources consulted for the assumed conversion cost included quality assessment of API purchased from the assumed third-party supplier in this cost.

Depending on the country in question, as many as $15 \%$ of medicines on the current EML may be under patent protection. ${ }^{27}$ We undertook our analysis before the 2017 list was published; patented medicines added in 2017 that could otherwise have been included were dolutegravir, raltegravir, velpatasvir, nilotinib and dasatinib.

Tamil Nadu state tender prices are likely to be lower than the prices normally encountered by patients in India, where most medicine purchases are out of pocket. ${ }^{17}$ Similarly, in the UK and South Africa the price sources represented hospital purchases and may thus represent the lower range of prices (for the UK, in a minority of cases BNF 'indicative prices' were used instead, which are in general derived from prices paid by pharmacies).

\section{CONCLUSION}

Estimation of generic prices can identify many medicines that are sold at prices far higher than would be expected based on their production costs. Most items listed in the WHO EML are sold in the UK and South Africa at prices significantly above those calculated from production costs. Generic price estimation and international price comparisons can be expanded to empower government price negotiations, and to support cost-effectiveness calculations at international and national levels. Assuming an absence of barriers to market entry, a wide range of the drugs on the EML can be profitably sold at very low prices in all countries. 
Contributors All authors designed the study, interpreted the data and critically reviewed the manuscript. MJB and DG collected and analysed the data.

Funding This study was funded by WHO.

Competing interests $\mathrm{AMH}$ reports no conflicts of interest. MJB reports funding from WHO for this work. DG reports funding from WHO for this work, as well as personal fees from the Medicines Patent Pool, STOPAIDS UK, and Global Justice Now, for work that took place after the completion of this analysis, and unrelated to this analysis.

Provenance and peer review Not commissioned; externally peer reviewed.

Open Access This is an Open Access article distributed in accordance with the Creative Commons Attribution Non Commercial (CC BY-NC 4.0) license, which permits others to distribute, remix, adapt, build upon this work non-commercially, and license their derivative works on different terms, provided the original work is properly cited and the use is non-commercial. See: http://creativecommons.org/ licenses/by-nc/4.0/

(C) Article author(s) (or their employer(s) unless otherwise stated in the text of the article) 2018. All rights reserved. No commercial use is permitted unless otherwise expressly granted.

\section{REFERENCES}

1. UN Secretary-General. The United Nations secretary-general's highlevel panel on access to medicines report: promoting innovation and access to health technologies. $2016 \mathrm{http}: / /$ www.unsgaccessmeds. org/s/UNSG-HLP-Report-FINAL-12-Sept-2016.pdf (accessed 21 Aug 2017).

2. Wirtz VJ, Hogerzeil HV, Gray AL, et al. Essential medicines for universal health coverage. Lancet 2017;389:403-76.

3. World Health Organization. The world medicines situation. 2004 http:// apps.who.int/medicinedocs/pdf/s6160e/s6160e.pdf (accessed 30 Nov 2017).

4. MDG Gap Task Force. Taking stock of the global partnership for development. 2015 http://www.un.org/millenniumgoals/pdf/MDG Gap_2015_E_web.pdf (accessed 21 Aug 2017).

5. Wagner AK, Graves AJ, Reiss SK, et al. Access to care and medicines, burden of health care expenditures, and risk protection: results from the World Health Survey. Health Policy 2011;100:151-8.

6. Hoen E', Berger J, Calmy A, et al. Driving a decade of change: HIV/AIDS, patents and access to medicines for all. J Int AIDS Soc 2011;14:15.

7. Laing R, Waning B, Gray A, et al. 25 years of the WHO essential medicines lists: progress and challenges. Lancet 2003;361:1723-9.

8. World Health Organization. Revised procedure for updating WHO's Model List of Essential Drugs. http://apps.who.int/gb/archive/pdf_ files/EB109/eeb1098.pdf?ua=1 (accessed 1 May 2017).

9. Fortunak JM, de Souza RO, Kulkarni AA, et al. Active pharmaceutical ingredients for antiretroviral treatment in low- and middle-income countries: a survey. Antivir Ther 2014;19(Suppl 3):15-29.

10. Hill A, Gotham D, Cooke G, et al. Analysis of minimum target prices for production of entecavir to treat hepatitis B in high- and lowincome countries. J Virus Erad 2015;1:103-10.

11. Hill A, Simmons B, Gotham D, et al. Rapid reductions in prices for generic sofosbuvir and daclatasvir to treat hepatitis C. J Virus Erad 2016;2:28-31.
12. Gotham D, Fortunak J, Pozniak A, et al. Estimated generic prices for novel treatments for drug-resistant tuberculosis. J Antimicrob Chemother 2017;72:dkw522-52.

13. Hill A, Redd C, Gotham D, et al. Estimated generic prices of cancer medicines deemed cost-ineffective in England: a cost estimation analysis. BMJ Open 2017;7:e011965.

14. Hill A, Gotham D, Fortunak J, et al. Target prices for mass production of tyrosine kinase inhibitors for global cancer treatment. BMJ Open 2016;6:e009586.

15. World Health Organization. Medicines/finished pharmaceutical products. https://extranet.who.int/prequal/content/prequalified-lists/ medicines (accessed 18 Aug 2017).

16. Chaudhuri $S$, West $A$. Can local producers compete with low-cost imports? a simulation study of pharmaceutical industry in lowincome Africa. Innovation and Development 2015;5:23-38.

17. Pandey KR, Meltzer DO. financial burden and impoverishment due to cardiovascular medications in low and middle income countries: an illustration from India. PLoS One 2016;11:e0155293.

18. Kassebaum NJ, Arora M, Barber RM, et al. Global, regional, and national disability-adjusted life-years (DALYs) for 315 diseases and injuries and healthy life expectancy (HALE), 1990-2015: a systematic analysis for the Global Burden of Disease Study 2015. Lancet 2016;388:1603-58.

19. World Trade Organization. Amendment of the TRIPS Agreement. https://www.wto.org/english/tratop_e/trips_e/wtl641_e.htm (accessed 4 Dec 2017).

20. Wilson C. Massive drop in London HIV rates may be due to internet drugs: New Scientist, 2017. https://www.newscientist.com/article/ 2117426-massive-drop-in-london-hiv-rates-may-be-due-to-internetdrugs/ (accessed 21 Aug 2017).

21. Hill A, Khwairakpam G, Wang J, et al. 96 \% SVR rates using impored generic DAAs for patients with hepatitis C. 2017. Abstract presented at CROI http://www.croiconference.org/sessions/ninety-six-svrrates-using-imported-generic-daas-patients-hepatitis-c (accessed 21 Aug 2017).

22. Kotwani A, Levison L. Price components and access to medicines in Delhi, India. 2007 http://apps.who.int/medicinedocs/documents/ s19208en/s19208en.pdf (accessed 21 Aug 2017).

23. Ministry of Chemicals and Fertilizers (Department of Pharmaceuticals). Order S.O. 1221(E). 2013 http://www.nppaindia. nic.in/DPCO2013.pdf (accessed 21 Aug 2017).

24. Central Board of Excise and Customs. Notification No. 140/2016. http://www.cbec.gov.in/htdocs-cbec/customs/cs-act/notifications/ notfns-2016/cs-nt2016/csnt140-2016.pdf (accessed 15 Jul 2017).

25. Republic of South Africa National Department of Health. Special requirements and conditions of contract. HP09-2016SD/01. The supply and delivery of solid dosage forms to the Department of Health for the period up to 31 July 2018. 2017 http://www.health.g ov.za/tender/docs/contructs/HP092016SD01ContractCircular.pdf (accessed 21 Aug 2017).

26. World Health Organization. WHO guidelines on country pharmaceutical pricing policies. 2015 http://apps.who.int/ medicinedocs/documents/s21016en/s21016en.pdf (accessed 21 Aug 2017).

27. Saez C. New WHO essential medicines list: Antibiotics, Hepatitis C, Leukaemia, TB. Intellectual Property Watch. 2017 https://www. ip-watch.org/2017/06/06/new-essential-medicines-list-antibioticshepatitis-c-leukaemia-tb/ (accessed 21 Aug 2017). 